\title{
Judgment and the Identity Theory of Truth
}

\section{Introduction}

The correspondence theorist of truth conceives of thought as separate from reality and of truth as consisting in a match between the two. The identity theorist disagrees: thought is answerable to reality for its truth - if a thought is true, this is because of the content of reality - but there is not the gap here that the correspondence theorist imagines. This disagreement has taken the shape of a disagreement over facts. According to a traditional correspondence theory, facts are those elements of external reality by which thoughts are measured: for a thought to be true is for it to correspond to a fact. The identity theory agrees that facts are elements of reality but denies that they are external to thought. Rather, a fact is a possible object of thought, it is something a subject may think, and thoughts - that is, thinkings - contain their objects.

The identity theorist's conception of facts as thinkables can be elaborated in more than one way. In this paper I shall consider two elaborations, one offered by Jennifer Hornsby and a second deriving from the Tractarian Wittgenstein and Ramsey. Hornsby's conception of a thinkable, and so of a fact, is informed by her adoption of the dual relation theory of judgment. As a result, I shall argue, she faces two significant problems regarding thought's answerability to reality. On the one hand a difficulty arises of how the content of reality is to be such that a thought could answer to it, and on the other there is a problem of how answerability can be possible without relapsing towards the correspondence theory. The Ramseyan version of the identity theory recommended in this paper involves, by contrast, a rejection of the dual relation theory of judgment and is not subject to either of the problems discussed.

\section{Opposing the Correspondence Theory}

As I shall understand it, the identity theory of truth has as its centrepiece an identification of thinkables - that is, possible objects of thought - and facts. The content of this identification lies, in part, in its opposition to the correspondence theory of truth.

\section{1}

We think, or say, that p. But how are we to characterise the that $p$ here? How are we to characterise what is thought or said in such an episode of thinking or saying, the object of the thinking or saying? McDowell writes:

When one thinks truly, what one thinks is what is the case. ... One can think, for instance, that spring has begun, and that very same thing, that spring has begun, can be the case. (McDowell 1994 p27) 
A thinkable - that $p$ - is something that can be the case: it can be the case that $p$. So much, for the identity theorist, is mere truism. It is a truism, furthermore, they want to recast. For the recasting, notice that the notion of being the case is readily aligned with that of a fact. So Wittgenstein, for example, writes:

The world divides into facts. Any one can either be the case or not be the case. (Wittgenstein $1922 \S \S 1.2-1.21)$.

The alignment can be made in two ways. One could straightforwardly identify a fact with something that can be the case. Or one could call something a fact only if it is the case. Both uses of the word are, I take it, perfectly legitimate. We no more hesitate to understand Wittgenstein when he identifies the totality of facts with everything that is the case (Wittgenstein 1922 §§1-1.1) than it crosses our mind to think he has only true representations in view when he writes that "we picture facts to ourselves" (Wittgenstein 1922 §2.1). 'It is a fact that $p$ ' entails ' $p$ '; but we speak also of nonobtaining facts. For reasons of simplicity and clarity only, I shall run with the 'non-factive' use of the word 'fact'. ${ }^{1}$ McDowell's (putative) truism is thus recast as the claim that a thinkable is a fact.

\section{2}

This identification of fact and thinkable stands in opposition to the correspondence theory of truth. In its simplest form, the correspondence theory holds that a thinking is true if, and only if, there exists a fact corresponding to it. On such a theory, facts would be external to thinkings - and so would not be the objects of thinkings. This opposition is no accident: it is a central ambition of the identity theorist to reject the correspondence theory. Clarification of the matter may be had by considering a second characterisation of thinkables.

McDowell, again, writes:

The basis of the truth-conditional conception of meaning, as I see it, is the following thought: to specify what would be asserted, in the assertoric utterance of a sentence apt for such use, is to specify a condition under which the sentence (as thus uttered) would be true. (McDowell 1998 p88)

If I were to utter the sentence 'Snow is white' assertorically, what I would assert is that snow is white, and just this, that snow is white, would be the condition of the truth of the sentence so uttered. (More simply, the sentence 'Snow is white' has as its truth condition that snow is white.) Again with thinkings: my thought that Jack loves Jill has as the condition of its truth precisely what I there think - that Jack loves Jill.

This characterisation of assertables/thinkables as truth conditions can, I think, be taken as uncontentious common ground between the identity and correspondence theorists. Both parties agree that a judgment has a truth condition - that $p$ - which belongs (essentially) to the judgment. From here, the theories diverge. The identity theorist, in identifying both thinkables and facts and

\footnotetext{
${ }^{1}$ As Wittgenstein later puts it: 'I can ... make the stipulation that I will only use the words 'fact', 'act' ... in a proposition which, when complete, asserts that this fact obtains. It would be better to drop the restriction on the use of these words, since it only leads to confusion, and say quite happily: 'This act was never performed', 'This fact does not obtain'. (Wittgenstein 1974 p77)
} 
thinkables and truth conditions, identifies truth conditions and facts. The fact that Jack loves Jill is the truth condition of my belief that Jack loves Jill. The simple correspondence theorist, on the other hand, imagines a quite different role for facts. A fact is not a truth condition but rather an item whose existence constitutes the obtaining of a truth condition - it is truth-maker. The fact that Jack loves Jill is not the truth condition of my belief that Jack loves Jill: it is, rather, an entity whose existence constitutes the obtaining of that truth condition and so the truth of my belief.

\section{3}

The identity theorist wants to oppose rather more, however, than just the simple correspondence theory. Indeed, to understand fully that particular opposition, we need to place it in the context of a broader and deeper stance against correspondence theories more generally. At root, the identity theorist's concern is not with the nature or role of facts - with whether, say, facts are to be taken as truth-makers or as truth conditions. The identity theorist's root concern, rather, is to reject the idea, basic to the correspondence theory in all its versions, that a judgment is something which is separate from reality and whose truth consists in a match with reality.

Hornsby, following McDowell, describes the correspondence theorist as positing an 'ontological gap' between thought and reality (Hornsby 1997 p1). On one side of the gap are judgments and on the other is reality; truth then consists in a match between the two. And it is in opposition to this supposed gap that Hornsby and McDowell locate reality - obtaining facts - inside thoughts. Reality is not an external object of comparison/assessment for thought; rather, as Wittgenstein writes, 'when we say, mean, that something is the case, we do not stop with what we mean anywhere short of the fact' (Wittgenstein 1953 §95). Or in another favoured quote: thought 'reaches right out to reality' (Wittgenstein 1922 \$2.1511).

This root opposition to the correspondence theory more generally may be sharpened up as before with the notion of a truth condition. The correspondence theorist's gap between thought and reality is the idea that, given a thought with its truth condition, there remains a question of what it is for the world to match that truth condition, a question of what is it for the world to be such that the truth condition obtains. Perhaps the obtaining of the truth condition consists in the existence of a fact, or perhaps some rather different account is to be given, one which doesn't speak of facts or even of existence. To offer some such account of the obtaining of a truth condition, however, is to be a correspondence theorist in the broad sense in view. The identity theorist's rejection of the correspondence theorist's gap then consists, from this perspective, in their rejection of the propriety such theorising. No account is to be offered of the obtaining of a truth condition by reference to an external reality. Rather, the truth condition is - if it obtains - already reality, and so its obtaining or non-obtaining is brute. ${ }^{2}$ As Russell puts it, some truth conditions obtain and some do not 'just as some roses are red and some white' (Russell 1904 p523).

\section{4}

To close the section, note that we can see in these last few remarks the principal reasons for and against using the word 'fact' factively. If facts are identified with truth conditions in general then reality cannot be, or include, the totality of facts: it must rather be the totality of obtaining facts and this is slightly clumsy. The restriction is necessary because it is a principal task of reality, as that

\footnotetext{
${ }^{2}$ No more account is to be offered of a truth condition's obtaining or non-obtaining than is offered by the simple correspondence theorist of the existence of non-existence of her facts. In both cases the philosophical theorist, having reached reality, stops theorising.
} 
notion is commonly conceived by philosophers, to explain judgments' truth, and if all facts, obtaining or otherwise, were a part of reality, then this task would not be achieved (more on this below). Telling in favour of a non-factive use of 'fact', on the other hand, is that if one were to use the word 'fact' for obtaining truth conditions only and then 'fiction', say, for non-obtaining truth conditions, someone might reasonably respond by asking what the difference is between the two, what account is to be given of a thinkable's being a fact as opposed to a fiction. Calling all thinkables facts, as I shall, discourages this question, implicitly suggesting from the top that one is not interested in offering a theory of the obvious division within the category. But to repeat, this is a purely terminological preference. Nothing changes in the discussion above or to follow if, when speaking of the identity theory, the word 'fact' is replaced every time by 'fact or fiction'.

\section{Two Conceptions of Thinkables}

The identification of facts and thinkables can be elaborated in more than one way depending on how thought, and so how the objects of thought, is conceived. This section contrasts two conceptions of thought and considers in outline how those conceptions lead to different versions of the identity theory.

\section{1}

Ramsey asserts in his 1927 paper 'Facts and Propositions' that once a theory of judgment has been given - a theory that is of the possession of a truth condition - there remains no further problem of truth, no further problem of the obtaining of a truth condition:

It is, perhaps, also immediately obvious that if we have analysed judgment we have solved the problem of truth. ... [All that] we have to explain is the meaning of saying that the judgment is a judgment that $a$ has $R$ to $b$, i.e. is true if $a R b$, false if not. (Ramsey $1990 \mathrm{p} 158$ )

This claim that there is no 'separate problem of truth' (p157) to the problem of judgment, as Ramsey puts it a page earlier, should sound familiar. It's worth emphasising in passing that Ramsey does indeed say 'separate problem of truth' and not simply 'problem of truth'. Ramsey's position is not that there is no problem of truth, but rather that the problem of truth is the problem of judgment the problem, that is, of what it is to be true if $p$, false if not. We should hesitate, I thus quickly suggest, to see Ramsey as a deflationist. But rather than take that exegetical point on directly, let's consider judgment.

Ramsey's paper opens with a Russellian distinction between dual and multiple relation theories of judgment. Judgment, according to the dual relation theory, is a relation between a subject (or 'mental factors') and a single entity judged. According to the multiple relation theory, on the other hand, judgment is a multiple relation between a subject (or 'mental factors') and several separate entities - between, that is, a subject and those entities which would on the dual relation theory have been the constituents of the single entity judged. This contrast is, of course, highly schematic. It is not without content, however; in particular, the two options carry divergent implications for how thinkables are to be conceived.

The dual relation theory holds, as said, that belief is a dual relation between a subject and a single entity. That single entity will then be the object of the belief, the thinkable there believed. It 
follows on such an account, then, that thinkables are existing entities. The relatum of a relation is an entity, an object, whose existence is a precondition of the relation's obtaining. And so the thinkable that $\mathrm{p}$ is, according to the dual relation theory, an entity whose existence is a precondition of judging that $p$. The multiple relation theory, on the other hand, has the consequence that thinkables are not entities. A judgment, according to the multiple relation theory, is a relation not to a single item but rather to several separate entities, and so there is no entity belonging to the judgment which is a candidate for being the thinkable there thought. If pushed on what an object of judgment is to be if not an entity, a multiple relation theorist might add that a thinkable is not a thing but rather a 'way things may be'; it is not an entity but a possibility. More concretely, it will be held that talk of the existence of a thinkable does not specify a precondition of judgment; rather, 'The thinkable that $p$ exists' will, if it means anything at all, most likely mean simply that $p$.

\section{2}

The identity theory of truth does not in itself carry any straightforward commitment to either the dual or multiple relation theory of judgment. ${ }^{3}$ So where Hornsby and the early Russell, for example, combine the identity theory with the dual relation theory, Wittgenstein and Ramsey, I shall suggest, are multiple relation identity theorists. As can be seen, however, the identity theory does take on rather different forms depending upon which theory of judgment is preferred. Let's pursue this point a little further.

First, consider truth-bearers. Ramsey writes:

According to some philosophers we apply [the terms 'true' and 'false'] to 'propositions', which are the objects of judgments and the meanings of sentences, but themselves neither judgments nor sentences.

According to the philosophers who believe in them, it is these propositions which are true or false in the most fundamental sense, a belief being called true or false by an extension of meaning according as what is believed is a true or a false proposition. But in as much as the existence of such things is generally (and to my mind rightly) doubted, it seems best to begin not with them but with the mental states of which they are the supposed objects and to discuss the terms true and false in their application to these mental states. (Ramsey 2001 p434)

If to judge that $p$ is to be related to a single thinkable-entity, then that entity must play a central role in the explanation of the judgment's truth value. And the obvious central role for it to play is that of conferring its own truth value on the judgment. Thus the dual relation theorist will most likely call thinkables propositions and take them to be the primary truth bearers. If, on the other hand, one follows Ramsey in rejecting the dual relation theory, and so rejects that there are such things as thinkables, then one will focus instead on judgments - mental states and sentences - as the bearers of the property of truth.

\footnotetext{
${ }^{3}$ One could object (-people have-) that identity is a relation and so if the identity theory of truth involves an identification of thinkables and facts it thereby involves treating thinkables as entities. The objection is misguided. The identity theory of truth is not some claim of the form ' $x=y^{\prime}$ - it is rather the theoretical position that, as I put it, no account is to be offered of the obtaining of a truth condition by reference to an external reality, for the truth condition is - if it obtains - already reality, and so its obtaining or non-obtaining is brute.
} 
This disagreement over truth bearers evinces, we can briefly note, a broader divergence in 'vision' of truth. Truth for the multiple relation theorist is a property of representations, whether mental or linguistic, and is indeed a species of representational correctness. For the dual relation identity theorist, on the other hand, truth is a property in the first instance of thinkables, and thinkables are not representations - they are rather what representations represent: facts. (Thinkables are not items with truth conditions: they are truth conditions.) Thus whilst the multiple relation theorist will hold, with the 1910 Russell, that 'there would be no truth and falsehood if there were no minds', the dual relation identity theorist takes truth to be a mind-independent property of mind-independent entities. ${ }^{4}$

A second notable point of difference between the dual and multiple relation identity theorists, one touched on just above, concerns such sentences as 'The fact/proposition/truth condition that $\mathrm{p}$ exists/is true/obtains'. Where the dual relation theorist will see reference made here to a thinkable entity which is then said to exist or to have the property of truth or of obtaining, the multiple relation theorist will provide a quite different account. More particularly, they will most likely see the sentences simply as periphrases of ' $p$ '. Thus Ramsey, taking a swipe at the correspondence theory, writes:

We can, if we like, say that [a judgment that $a R b$ ] is true if there exists a corresponding fact that $a$ has $R$ to $b$, but this is essentially not an analysis but a periphrasis, for "the fact that a has $R$ to $b$ exists" is no different from "a has R to b". (Ramsey 1990 p158-9)

And in a similar vein:

"it is true that Caesar was murdered" means no more than that Caesar was murdered, and "it is false that Caesar was murdered" means that Caesar was not murdered. (Ramsey 1990 p157)

We can equally imagine Ramsey asserting that "the truth condition that $p$ obtains" is no different from " $p$ ". These sentences are, of course, only the tip of the iceberg: there is a wide family of sentences (including, e.g., "Jack and Jill thought the same thing") of which the dual and multiple relation theorists will give divergent accounts. It is not however the concern of this paper to pursue this matter in any detail. Let's end the section by noting, rather, that in rejecting the idea that facts are existents - in either rejecting or analysing away talk of the existence of thinkables - the multiple relation identity theorist puts a wedge between the notions of reality and existence. Reality - that to which thought is answerable - is commonly thought of as a totality of existents. But the multiple relation identity theorist will hold both that reality is, or includes, the totality of ways things are, and also that to say that a certain way things are exists will, if it means anything at all, mean only that things are indeed that way.

\section{A Problem of Falsity}

\footnotetext{
${ }^{4}$ There is a point of possible concern here for the dual relation identity theorist - a concern whose first expression would be to suggest that the notion of a true fact is genuine misnomer as opposed to harmless tautology. The matter can't be taken further in this paper, however - though it connects into the discussion of section 5 below.
} 
There are two significant problems faced by a dual relation identity theorist neither of which takes a grip for an identity theorist who conceives of facts as ways things may be. Both problems may be found, in germ, in Russell and Ramsey's reasons for rejecting the dual relation theory. This section discusses the first of these two, a problem of falsity.

\section{1}

In 1910 Russell argues against the view that 'every judgment, whether true or false, consists in a certain relation, called "judging" or "believing", to a single object, which is what we judge or believe' (Russell 1992 p118). He writes:

Assuming that there are such objects, let us, following Meinong, give them the name 'Objectives'.... . So long as we only consider true judgments, the view that they have Objectives is plausible ... . But what is the Objective of the judgment "Charles I died in his bed"? (Russell 1992 pp.118-9)

And again:

If we allow that all judgments have Objectives, we shall have to allow that there are Objectives which are false. Thus there will be in the world entities, not dependent upon the existence of judgments, which can be described as objective falsehoods. (Russell 1992 p119)

This, Russell thinks, is considerably implausible. Ramsey concurs with Russell's opinion, speaking somewhat later, but with reference to Russell, of 'the incredibility of the existence of such objects as "that Caesar died in his bed", which could be described as objective falsehoods' (Ramsey 1990 p1534).

To be clear, the target of Russell and Ramsey's discussions is not simply the dual relation theory but rather the combination of that theory with the position that a judgment's 'objective' belongs to the world - it is a fact, or if we use that word more sparingly, it is a fact-or-fiction. The target, that is to say, is a dual relation identity theory. And the complaint is straightforward. The dual relation identity theorist has common ground with the simple correspondence theorist in that both parties conceive of facts as existing entities. (As Strawson would disparagingly put it, both parties conceive of facts as 'chunks of reality' (Strawson 1950 p153).) But once the identity theorist has gone that far with the correspondence theory, it's unclear how to avoid going all the way and conceiving of facts as truth-makers, as entities that exist only in case of truth. If I think that Charles I died in his bed, then on the dual relation identity theory there must exist such a fact-entity as that Charles I died in his bed. But this in turn entails - surely - that Charles I died in his bed.

\section{2}

As Ramsey and Russell give it, this is argument by incredulous stare. How can there exist such a factentity as that Charles I died in his bed when he actually died on the scaffold? And as sharp as the 
stare may be, it allows, dialectically, for a brazening out. Indeed, Hornsby implicitly does just this. ${ }^{5} \mathrm{~A}$ recasting is possible, however, which doesn't allow for such a short response.

It was mentioned in passing above that it is a principal task of reality, as that idea is commonly conceived by philosophers, to explain judgments' truth. If my belief is true, this is explained by the content of reality. And the point made briefly on the heels of that observation was that if reality is to be up to this task, the identity theorist cannot have it include both obtaining and non-obtaining truth conditions. If reality includes both that Jack loves Jill and that Jack does not love Jill, then it is unclear at best how it might explain the truth of my belief that Jack loves Jill. Hornsby, I think, recognises this point and so follows McDowell in echoing Wittgenstein's dictum that the world is a constellation of facts (Wittgenstein $1922 \$ 1.1$, Hornsby 1997 p2) - where by 'fact' she means, like Wittgenstein here, an obtaining truth condition. But how, one might wonder, is Hornsby entitled to this Wittgensteinian identification of the world? If fictions (non-obtaining truth conditions) exist just as well as facts, then on what grounds are they being excluded from reality? Reality is, for Hornsby, a totality of existents, so how is it, given that they both exist, that facts are included in reality but fictions excluded? The dual relation identity theorist cannot, I think, brazen this out: a significant response is demanded. Either the idea must be rejected of a reality whose content explains judgments' truth, or it must be explained how certain existing items but not others - facts but not fictions - get to count as belonging to reality.

The former option is of course perfectly possible - and one thinks here of Frege. To make this move is, however, to shift the game substantially. First, it dialectically weakens the identity theorist's repudiation of the correspondence theory. The desire to make good on an idea that thought answers to reality is, I take it, a principal motivation of the correspondence theory; if the idea is rejected rather than accommodated then the correspondence theorist may decide to stop listening. Second, and relatedly, the content of one's position as an identity theorist becomes somewhat thinner. The identification of fact and thinkable as we understood it above had two arms. On one side it included the negative stance that there are no facts other than thinkables: philosophical theorising with a notion of fact categorially distinct from thinkable is misguided. And

\footnotetext{
${ }^{5}$ Indeed, she misreads Russell and fails even to recognise a problem here. In response to Russell's remarks on falsity Hornsby writes:

Moore and Russell can both be read as abandoning an identity theory of truth as a consequence of coming to believe that it rendered falsehood totally unaccountable. ... I believe that Russell's difficulty with falsehood stemmed from his (non-Fregean) account of the unity of propositions, which made it impossible for a proposition to be both unified and untrue. (Footnote: According to Russell, what makes the proposition that $R a b$ a unity is the fact that $R$ relates $a$ and $b$.) (Hornsby 1999 p244)

Russell's problem of falsity for his 1903 theorising, Hornsby suggests, depends upon a certain view of the constitution of thinkables. More particularly, it depends upon thinkables being constituted in the manner of the early Russell and not in the manner of Frege. Fregean dual relation identity theorists such as herself face no problem here. This suggestion is, however, a misreading of the texts. It is certainly true that Russell is reacting in 1910 against his own earlier version of the dual relation theory. It is also true the early Russell took thinkables to be constituted rather differently from Frege; where in 1903 Russell took the thinkable that Jack loves Jill to be a complex object composed of Jack, love and Jill, Frege has it composed of elements of sense. And it is further true that this difference between Frege and the early Russell means that there is $a$ problem of falsity faced only by Russell. How, one may ask the early Russell, can Jack love and Jill be unified into a complex whole if Jack does not love Jill? But all this granted, it remains implausible that this 'unity' problem is the problem Ramsey and the 1910 Russell are finding for the dual relation theory. One cannot so much as give a first pass statement of this problem without speaking of the entities Jack, love and Jill being united into a thinkable - but neither Russell nor Ramsey mention what the thinkable's constituents might be. The problem Russell presents here, I take it, turns rather on what Russell and Ramsey do speak of: the idea that thinkables are existing objects.
} 
on the other side - and partially justifying the negative stance - it involves the positive position that thinkables are nothing less than facts: nothing less, that is, than elements of reality. If, however, we reject the idea of a reality to which thought answers, then the content of this second arm comes under threat: of what reality are thinkables now to be elements? The identity theorist's position, the worry would then be, will lose much of its interest, becoming little more than a negative stance, not easily justified in its generality, against non-thinkable facts.

As noted, however, Hornsby's appeal to Wittgenstein's non-Fregean notion of 'world' seems clearly and reassuringly to imply that she does not want to take this route. ${ }^{6}$ Her problem is thus to justify her identification of the world as the totality of (obtaining) facts. (Without justification the identification will be mere stipulation, and a merely stipulated totality won't do any explanatory work; in particular, it won't explain the truth of my judgment.)

\section{3}

There is, by contrast, no problem of falsity for the identity theorist who conceives of thinkables as ways things may be there - no problem, that is, of having reality include obtaining truth conditions only. Such a theorist does not face a question of existence pushing both obtaining and nonobtaining thinkables towards a common status in reality. Rather, thinkables form a space of possibilities - truth conditions - amongst which some are realised: and the realised possibilities, the actualities, constitute the world. As Wittgenstein puts it: 'The facts in logical space are the world' (Wittgenstein $1922 \S 1.13)^{7}$

\section{A Problem of Explaining Truth}

The problem of falsity for the dual relation identity theorist is a problem of how reality is to be such that thought could answer to it. The second problem I want to consider grants for purposes of argument that reality contains obtaining truth conditions only. Even with this in place, the further problem then runs, it is unclear how the dual relation identity theorist can, consistently with her intentions as an identity theorist, make good on answerability.

5.1

Ramsey summarises Russell's 1910 arguments against his earlier 1903 dual relation identity theory as follows:

Let us begin with the objective factor or factors [in a judgment]; the simplest view is that there is one such factor only, a proposition, which may be either true or false, truth and falsity being

\footnotetext{
${ }^{6}$ It is, I however think, the option Julian Dodd implicitly takes in his book (Dodd 2000). Indeed, the reason Dodd's book is not discussed in this paper is that he is not concerned there with the idea of thought's answerability to reality.

${ }^{7}$ One might be tempted to respond that the realised and unrealised possibilities spoken of here must nonetheless themselves must have some common status in reality - they must all be real possibilities, in some sense - and so the problem sticks also for the multiple relation identity theorist. Faced with such an objection, the multiple relation identity theorist would doubt that any content has been given to the word 'real'. Looking to Wittgenstein, logical space is precisely not to be thought of as having a boundary outside which lie 'non-real (impossible) possibilities' ('such-and-such possibilities are real, but not such-and-such others'). The notion of a possibility is not in this way contrastive.
} 
unanalysable attributes. This was at one time the view of Mr. Russell, and in his essay, "On the Nature of Truth and Falsehood," he explains the reasons which led him to abandon it. These were, in brief, the incredibility of the existence of such objects as "that Caesar died in his bed," which could be described as objective falsehoods, and the mysterious nature of the difference, on this theory, between truth and falsehood. He therefore concluded, in my opinion rightly, that a judgment had no single object, but was a multiple relation of the mind or mental factors to many objects. (Ramsey 1990 pp.153-4)

We've considered the problem of incredible objective falsehoods; let's turn now to the mysterious nature of the difference between truth and falsehood.

The complaint here is not quite that on Russell's early theory truth and falsity were brute properties of propositions. It can't be quite that because Ramsey rejects in this paper that there are such things as propositions. 'It is true that $p$ ' means nothing other than that $p$, 'it is false that $p$ ' nothing other than that not-p, and the last thing Ramsey would press for is would press for is an account of the difference between Jack's loving Jill and his not loving Kate. So the complaint must rather be - as context confirms - that Russell's 1903 theory makes the difference between true and false judgment mysterious. But what complaint is that? What sort of an explanation of this difference are Ramsey and the 1910 Russell after? Well, it is clear in both texts that what they want is an explanation by reference to, as we've put it, the content of reality. Whether my judgment is true or false must depend upon 'the world'. We considered above that if the world contains too much, if it contains non-obtaining facts as well as obtaining facts, such an explanation will not be forthcoming. Excluding non-obtaining facts from reality is, however, only a precondition of an explanation. With this precondition in place, one still needs that what is included in reality obtaining truth conditions - does some explaining. Specifically, one needs it to be the case that if Jack loves Jill, then just this - that Jack loves Jill - explains the truth of my judgment that Jack loves Jill. $^{8}$

\section{2}

The 1903 Russell endorses no such explanation. The truth of a judgment that Jack loves Jill, he held, is a matter of the truth of the proposition judged. But the truth of the proposition judged was in turn neither equated with, nor taken to be explained by, Jack's loving Jill. It was not equated with Jack's loving Jill because Russell's dual relation theory had propositions down as objects, and such an object having the property of truth is a different matter from Jack and Jill being related by love. And it was not explained by Jack's loving Jill because it was not explained by anything. As Ramsey emphasises in making his complaint, truth and falsehood are, for Russell, brute 'unanalysable attributes' of proposition-entities.

Why this bruteness? Well, recall that it was taken in section 2 above to be a part of the identity theory's essential opposition to the correspondence theory that it refuses to provide an account of the difference between obtaining and non-obtaining truth conditions. The reason for this was straightforward: in holding that truth conditions, if they obtain, are already reality, the identity theorist rejects that there is anything else, any 'further reality', by reference to which their obtaining or non-obtaining might be explained. Thus, as Russell had it, some truth conditions obtain and some

\footnotetext{
${ }^{8}$ Or as Aristotle had it: 'It is not because we think that you are white, that you are white, but because you are white we who say this have the truth' (Aristotle 1984 1051b 6-8).
} 
do not, 'just as some roses are red and some white' (Russell $1904 \mathrm{p523)}$ ). The fuller quote from Russell, however, is that 'some propositions are true and some false just as some roses are red and some white.' And the point of remarking this here is that these two claims are, of course, the same; I wasn't misquoting Russell. For a dual relation identity theorist - a theorist who takes thinkables to be the primary truth bearers - no separation is available of the truth of the thinkable that $p$ from its obtaining. ${ }^{9}$ So not to give an account of the difference between thinkable obtaining and nonobtaining is precisely not to give an account of the difference between thinkable truth and falsity.

Hornsby, it may thus seem, will have to agree with the 1903 Russell that thinkable truth and falsity to be brute, and so follow him to the unwelcome conclusion that the truth of my judgment that Jack loves Jill is not explained by Jack's loving Jill. ${ }^{10}$ Interestingly, though, this is not what happens. Whilst Hornsby agrees with Russell that judgment truth is a matter of propositional truth, she rejects that propositional truth is brute. Rather, the truth of the proposition that Jack loves Jill and so the truth of my judgment - is explained by, precisely, the fact that Jack loves Jill. Hornsby, this is to say, agrees, as an identity theorist must, that the truth of a thinkable is not explained by any further reality. There is no reality beyond the thinkable to which appeal might be made here. But the conclusion that thinkable truth must therefore be brute is, she implies, too hasty. Rather, the truth of a thinkable is explained by the thinkable itself. Appealing as this proposal may seem, it does not, I want now to press, represent a happy way for the dual relation identity theorist to have thought answerable to reality. In particular, I want to suggest that Hornsby's position here threatens to push her towards the correspondence theory in a manner with which she should be considerably uncomfortable, given her ambitions in offering an identity theory.

\section{3}

It is clear enough why Hornsby would want to claim that if the proposition that $p$ is true, this is because $p$. Without this she is left with the early Russell unable to say that if my judgment that $p$ is true this is because $p$, and so unable to endorse the idea that thought answers to reality. How though is the claim to be substantiated? Addressing this question, Hornsby compares the relationship between 'The thinkable that $a$ is $F$ is true' and ' $a$ is $F$ ' with that between ' $\{a\}$ has a member that is $F$ ' and ' $a$ is $F$ '. Much as a's being $F$ explains $\{a\}$ 's having a member that is $F$, so too it explains the thinkable that a is F's being true. Her leading idea here is that the proposition's being true, like the set's having a member that is $F$, 'requires something more than a's being F' (Hornsby $2005 \mathrm{p} 44)$ - and this something more constitutes the explanatory asymmetry. Substituting 'The rose is red' for 'a is F' she writes:

For the rose to be red, it isn't required that there should be anything meaningful to say or to think; in particular it isn't required that the proposition that the rose is red should be propounded. Again, for the rose to be red it isn't required that one should be able to speak or to think of a set whose sole member is the rose. (Hornsby 2005 pp.43-4)

\footnotetext{
${ }^{9}$ One could try, perhaps, for something like: the thinkable's truth is constituted by, rather than identical to, its obtaining, but transparently there is no material available to the theorist with which to substantiate such a claim.

${ }^{10}$ As Russell writes in 1910: if we 'adhere to the opinion that there are both true and false Objectives we shall be compelled to regard it as an ultimate and not further explicable fact that Objectives are of two sorts, the true and the false' (Russell 1992 p119).
} 
$\{a\}$ 's having a member which is $F$ requires something more than a's being $F$ : it requires that the singleton $\{a\}$ should exist. Similarly, 'its being the case that [the proposition that $p$ ] is true requires more (in the sense elicited) than that $p$ should be the case' ( $p 44$ ): it requires that there should be such a proposition as that $\mathrm{p}$.

How, one however wonders, does the 'The proposition that $p$ is true' say more than ' $p$ '? Preliminary substance is available for the claim that it says something different from ' $p$ ' - it speaks of a thinkable-entity and a property of truth neither of which are spoken of by ' $p$ '. But how something more? In the case of the singleton $\{a\}$, the claim that a's being $F$ explains $\{a\}$ 's having a member which is F doesn't come for free: it is grounded, rather, in the theory of sets and their membership. This is what accounts for the 'saying more than' explanatory relation. And no more can it come for free that a's being $\mathrm{F}$ explains the proposition-entity that a is F's having the property of truth. For that, it seems, we shall need (nothing less than) a theory of propositions and their truth.

One point of concern, then, might be that it's unclear what sort of theory Hornsby could offer here. She can't suggest that the truth of the proposition that a is $F$ depends upon a's being $F$ by virtue of its representing that $a$ is $F$, as this is obviously incompatible with the identity theory. To repeat a point made above, thinkables are not representations, they are what representations represent - facts. (The proposition that $a$ is $F$ does not represent that $a$ is $F-$ it is that a is F.) Nor can Hornsby make the dependence in some way definitional - not without, that is, her theory of truth collapsing into a minimalism. (And Hornsby is quite clear she doesn't want that: like Frege, Wittgenstein, Ramsey and many others, she is adamant that the notion of thought, of thinking and of thinkable, is not theoretically prior to that of truth. ${ }^{11}$ ) What Hornsby would point us to here instead, I rather take it, is the work of Davidson. I can't begin here to assess the prospects of such an appeal. What I want rather to do is query the fact that Hornsby so much as needs a theory, of whatever sort, of the truth of propositions. The concern I want to press, this is to say, is not that it is unclear what Hornsby might say at this point but rather that we have here a point at which something needs to be said.

\section{4}

In adopting the identity theory and rejecting of the correspondence theory, Hornsby, following McDowell and Wittgenstein, wants to insist that thought and reality are internally connected. To repeat the (retrospecting) later Wittgenstein: 'When we say, when we mean, that something is the case, we do not stop with what we mean anywhere short of the fact' (Wittgenstein 1953 §95). Now Hornsby has that perfectly well, but the way in which she has it - the conceptions of meaning and fact she brings there into play - causes a second internal connection between thought and reality to become obscure. How is it, the question opens up, that the truth of my judgment that Jack loves Jill is a matter of Jack's loving Jill? The response to this question in keeping with the Identity Theorist's attitude towards truth should be that we have here mere truism: for my judgment to be a judgment that Jack loves Jill just is for its truth to be constitutively explained by Jack's loving Jill. Hornsby, the concern however is, is out of position to make such a response. For my judgment to be a judgment that Jack loves Jill, she holds, is for it to have as its object the proposition-entity that Jack loves Jill and it remains obscure, a point in need of substantial account, how the truth of that entity and so the truth of the judgment will depend upon things being a certain way with Jack and Jill. McDowell

${ }^{11}$ See Hornsby 1997 section III. 
claims, and indeed attributes the claim to Hornsby, that 'the only general statements we can acceptably make about truth are truistic' (McDowell 2005 p88) - but Hornsby must, I think, refuse the attribution. Her theorising leaves her needing to make and justify a substantial - non-truistic theoretical claim that if the thinkable that $p$ is true this is because $p$.

We can voice the concern here with the terminology of gaps. Hornsby's identification of true thinkables and facts aims to repudiate the correspondence theorist's idea of a gap between thought and reality. But the manner of her identification effectively opens up a second such gap. This second gap is, if you like, a gap in the first instance within reality. In having thinkables as things, Hornsby places them alongside, and so at a distance from, other, more normal things such as Jack and Jill. In so having thinkables, this is to say, there arises a question of how matters being as they are with the thinkable-things - in particular their being true and their entailing each other - relates to matters being as they are with the non-thinkable things - their being red, loving each other etc.. One needs a bridging theory. And whilst the gap in need of a bridge is, as said, a gap in the first instance between two sections of reality, once the absence of a gap between thought and one of these sections - the world of thinkables - is made clear, what we are left with is a precisely gap between thought and the world of Jack and Jill. Hornsby thus ends up looking rather like the correspondence theorist she wants to oppose. ${ }^{12,13}$

\section{5}

The identity theory of truth, I am suggesting, cannot find its proper expression until the dual relation theory of judgment is rejected; only then can the identity theorist have thought answerable to reality without therewith opening up a gap between the two. And once the dual relation theory is rejected the identity theorist can indeed have gapless answerability. Once the dual relation theory is rejected and thinkables conceived of as ways things may be, no separation is effected between thinkables and Jack and Jill. Rather, Hornsby's world of thinkables is replaced by Wittgenstein's logical space of possibilities, and the layout of her world of thinkables becomes the determination of that space - it becomes, that is to say, nothing other than the layout of the world of Jack and Jill. ${ }^{14}$ To repeat the point: once the dual relation theory is rejected, the claim that the truth of my judgment is explained by Jack's loving Jill can become mere truism. To say that a judgment has that Jack loves Jill as its truth condition - to say that it is a judgment that Jack loves Jill - is, trivially, to say that the obtaining of that condition constitutively explains the truth of the judgment. And to say

\footnotetext{
${ }^{12}$ One perspective on the point here, misleading no doubt for certain purposes, would be that Hornsby has not so much avoided a gap between thought and reality so much as located thinkables on the thought side of such a gap - and so undermined her right to think of (true) thinkables as facts.

${ }^{13}$ Hornsby might reply that I'm running together here two types of gap, that the 'ontological gap' she wants to avoid between thought and the world is a particular kind of theoretical gap, and that the theoretical gap I'm finding her committed to is not of the same kind. Maybe. Certain things she says in her 1997 paper seem to suggest that she sees the correspondence theorist's gap as between the conceptual (thought) and the nonconceptual (world). And the gap I've got in view is certainly not of this kind: the proposition's truth is explained for Hornsby not by things being as they are with non-conceptual grit but rather by the proposition itself. It is readily pointed out, though, that whilst some correspondence theorists clearly are operating with such a gap (e.g. Travis (2011)), others (e.g. the 1910 Russell) are clearly not. And what the identity theorist should be after - surely - is a repudiation of the disunity of thought and world found in correspondence theories generally. (This is I think McDowell's ambition; it is certainly the early Wittgenstein's (see Sullivan 2001).)

${ }^{14}$ For an account of the lack of a gap between thought and reality in the Tractatus, and of Wittgenstein's attitude towards Frege on the matter, see Sullivan 2001.
} 
this, for Ramsey, is not to say anything other than that Jack's loving Jill constitutively explains the truth of the judgment. The obtaining of the truth condition that Jack loves Jill is not the possession by some thinkable entity of the property of truth/obtaining: it is nothing other than Jack's loving Jill. ${ }^{15}$

\section{Conclusion}

It is well known that Russell moves in 1910 not only to a multiple relation theory of judgment but also to a correspondence theory of truth. We have explored the reasons he gives for adopting the multiple relation theory. It's not the case, however, that Russell advances further reasons, reasons beyond his concerns with thought's answerability to reality, to justify his move to a correspondence theory. On the contrary, the correspondence theory, Russell implies, is where one is taken when one takes such answerability seriously. So immediately after saying that his earlier theorising 'leaves the difference between truth and falsehood quite inexplicable' he writes:

We feel that when we judge truly some entity "corresponding" in some way to our judgment is to be found outside our judgment, while when we judge falsely there is no such "corresponding" entity. (Russell 1992 p119)

Wittgenstein and Ramsey disagree that this is the proper terminus of Russell's concerns with answerability. What those concerns call for is only a rejection of the dual relation theory of judgment; they do not in addition provide pressure for a correspondence theory of truth. Russell's 'feeling' that for Jack to love Jill is for there to exist a fact-entity of Jack's loving Jill is an entirely separable and somewhat dubious consideration. Dubious or not, I have argued that the feeling is at least separable. Once the dual relation theory is rejected, an identity theorist of truth can endorse perfectly well the claim that if my belief is true this is because of the content of reality.

\section{References}

Aristotle 1984: Metaphysics in Barnes ed. The Complete Works of Aristotle (Princeton: Princeton University Press)

\footnotetext{
${ }^{15}$ It's worth briefly considering how Frege would react to the line of argument of this section. Frege appears, at least, to maintain with Hornsby that thinkables are entities, the primary truth bearers (e.g. Frege $1984 \mathrm{pp}$. 353-4), and then also with Ramsey that 'The thinkable that $p$ is true' says the same as ' $p$ ' (Frege 1984 p354). Such a combination of views obviously calls for elaboration: if thinkables are entities then 'The thinkable that $p$ is true' would seem to involve reference to such an entity and the ascription to it of the property of truth. If not, then how not? If so, then how does the sentence nonetheless say the same as ' $p$ '? (Frege is unusually uncomfortable here, uncertain whether we should think of truth as 'a property in the ordinary sense' (Frege 1984 p354).) This need for elaboration to one side, however, the only explanation available to Frege of the truth of a judgment would appear to be that stemming from thinkables being the primary truth bearers. Whilst Frege can say that a judgment that $p$ is true because $p$, the explanation in view here is nothing more than the position that a judgment that $p$ is true because its object, that $p$, is true. In particular, it does not include the position that the primary truth bearer - the judgment's object - is true because of reality. The explanation thus fails to embody an idea of thought answering to reality; Russell and Ramsey would not be happy. (This 'failure' is of course not surprising: as noted above, Frege simply doesn't deal in a notion of reality to which thought is answerable.)
} 
Dodd 2000: An Identity Theory of Truth (New York: Palgrave MacMillan)

Frege 1984: 'Thoughts' in Collected Papers on Mathematics, Logic and Philosophy (Oxford: Blackwell) Hornsby 1997: 'Truth: The Identity Theory', Proceedings of the Aristotelian Society

Hornsby 1999: 'The Facts in Question: A Response to Dodd and Candlish', Proceedings of the

Aritotelian Society

Hornsby 2005: 'Truth without Truthmaking Entities' in Beebee and Dodd eds. Truthmakers (Oxford:

OUP)

McDowell 1994: Mind and World (Cambridge, Mass.: Harvard University Press)

McDowell 1998: 'In Defence of Modesty' in Meaning, Knowledge and Reality (Cambridge, Mass.:

Harvard University Press

McDowell 2005: 'The True Modesty of an Identity Conception of Truth: a Note in Response to Pascal

Engel' International Journal of Philosophical Studies 13 pp. 83-88

Ramsey 1990: 'Facts and Propositions' in Philosophical Papers (Cambridge: CUP)

Ramsey 2001: 'The Nature of Truth' in Lynch ed. The Nature of Truth ( MIT Press)

Russell 1904: 'Meinong's Theory of Complexes and Assumptions III' Mind 13 pp. 509-524

Russell 1992: 'On the Nature of Truth and Falsehood' in Logical and Philosophical Papers 1909-13

(London: Routledge)

Strawson 1950: 'Truth', Proceedings of the Aristotelian Society Supp. Volume 24 pp. 129-156

Sullivan 2001: 'A version of the picture theory' in Vossenkuhl (ed.), Wittgenstein: Tractatus -

Klassiker Auslegen. Akademie Verlag, Berlin, pp. 89-110

Travis 2011: Objectivity and the Parochial (Oxford: OUP)

Wittgenstein 1922: Tractatus Logico-Philosophicus (London: Routledge)

Wittgenstein 1953: Philosophical Investigations (Oxford: Blackwell)

Wittgenstein 1974: Philosophical Grammar (Oxford: Blackwell) 